\title{
РОССИЙСКАЯ РЕВОЛЮЦИЯ 1917 ГОДА В РЕГИОНАЛЬНОМ ПРЕЛОМЛЕНИИ: ПРОБЛЕМЫ ПОЗНАНИЯ
}

\author{
А. В. Шалак \\ Байкальский государственный университет, г. Иркутск, Российская Федерация
}

Информация о статье

Дата поступления

12 марта 2018 г.

Дата принятия к печати 21 мая 2018 г.

Дата онлайн-размещения 8 июня 2018 г.

\section{Ключевые слова}

Сибирь; Октябрьская революция; протестные настроения; интерпретация

\begin{abstract}
Аннотация
Существуют различные подходы к интерпретации политических процессов, происходивших в 1917 г. В связи с этим проблема установления причин радикальных протестных явлений, вылившихся в крупнейшую социальную революцию в истории России, актуальна. Одним из направлений решения данной научной проблемы является сопоставление политических процессов в центре и регионах. На основе исследования источников причин возможных протестных настроений в Сибири (на примере Иркутской губернии) утверждается, что в регионе отсутствовали проблемы, которые невозможно было разрешить в рамках существующей политической системы. Более того, участие в Первой мировой войне способствовало сплочению общества и власти. Ситуация начала радикально меняться после государственного переворота в фреврале 1917 г. Реформы, запущенные Временным правительством, неизбежно вели к приходу к власти большевистской партии. Октябрьская революция в Петрограде явилась прямым следствием политики Временного правительства. Исходя из этого концептуальное осмысление политических процессов, приведших к Октябрьской революции, требует закрытия многочисленных лакун в историческом познании, связанных с инспирированием данных процессов в столице России в феврале 1917 г. Поскольку ни одна масштабная революция в $\mathrm{XX}$ в. не происходила без влияния внешнего субъекта, события 1917 г. требуется вписать в мировой контекст. Только в этом случае возможно полноценно определить влияние внутреннего субъекта и выстроить концепцию политических процессов, завершившихся утверждением советского проекта.
\end{abstract}

\section{THE RUSSIAN REVOLUTION OF 1917 FROM THE REGIONAL PERSPECTIVE: PERCEPTION ISSUES}

\author{
Alexander V. Shalak \\ Baikal State University, Irkutsk, the Russian Federation
}

Article info

Received

March 12, 2018

Accepted

May 21, 2018

Available online

June 8, 2018

\section{Keywords}

Siberia; October Revolution; protest moods; interpretation

\begin{abstract}
There are different approaches to interpretation of the political processes in 1917. Therefore, the problem of revealing the reasons for the drastic protest events, resulted in the greatest social revolution in the Russian history, is a topical scientific issue. One of the directions in solving this scientific issue is comparing political processes in the centre and regions. It is stated on the basis of studying the sources of reasons for possible protest moods in Siberia (as in the case of Irkutsk Governorate) that there were no problems in the region which could not be solved within the framework of the existent political system. Moreover, participation in the First World War contributed to consolidation of society and
\end{abstract}


authorities. The situation started to change drastically after the coup in February 1917. The reforms launched by the Provisional Government inevitably lead to accession to power of Bolshevik Party. The October Revolution in Petrograd was a direct consequence of the Provisional Government policy. Due to this, conceptual understanding of political processes which lead to the October Revolution, requires filling in numerous gaps in historical perception connected with incitation of these processes in the capital of Russia in February 1917. As far as no ambitious revolution of the $20^{\text {th }}$ century happened without external influence, the events of 1917 need to be put into the global context. Only in this case one can fully estimate the internal influence and build an adequate paradigm of political processes, which were completed with implementation of the Soviet project.

В 2017 г. исполнилось сто лет Октябрьской революции. Несмотря на вековой юбилей и огромное количество изданной по истории Октября литературы, в изучении политических процессов 1917 г. остается много вопросов. Проблема не только в глубине исследования вопросов, но и в объяснении накопленного материала.

Официальная советская историческая наука в интерпретации Октября руководствовалась концепциейИ.И. Минца, которая в 1960-е гг. приобрела вполне завершенный характер [1]. Эта концепция объясняла политические процессы с позиций формирования объективных и субъективных предпосылок социалистической революции именно в России. Такой подход имеет право на существование, но его слабые стороны очевидны. Во-первых, первоначально речь шла о мировой революции, где Россия рассматривалась в качестве стартовой площадки. До 1927 г. события в октябре 1917 г. именовались военным переворотом, гимном СССР до 1936 г. являлся «Интернационал», а серп и молот символизировали союз российского крестьянства и немецкого рабочего класса. Политическая элита в этот период больше говорила и писала о некоем интернациональном долге, чем о реализации национально-государственных интересов.

Во-вторых, концепция И. И. Минца противоречила теории Маркса, с позиций которой интерпретировался конкретноисторический материал. В России отсутствовали материальные предпосылки для реализации подобного социального проекта. Этот аспект широко обсуждался как в политических дискуссиях непосредственно в первые годы после октябрьских событий 1917 г., так и накануне распада советской государственности.

Кардинальная переоценка традиционного подхода, изложенного в концепции И. И. Минца, началась в конце 1980-х.
В современной отечественной историографии причины Великой российской революции трактуются предельно широко. По-прежнему сильны позиции традиционной концепции И. И. Минца. В других работах делается акцент на ответственности элиты, качество которой не позволило достойно ответить на вызовы времени. Третьи ответственность за радикализацию общественных настроений и раскол общества возлагают на либеральную интеллигенцию. По сути, во втором и третьем подходах речь идет об одном: провоцировании столичной революции, сознательном или бессознательном, последствия которой получили развитие и в регионах. Не будь этого, не было бы и советского проекта.

В рамках другого направления особое внимание уделяется внешнему фактору в провоцировании событий 1917 г. Одни связывают февральский переворот с заговором масонства. В начале XX в. в России расплодилась масса масонских лож, запрещенных Александром II в 1822 г. Из 11 членов Временного правительства десять были масонами. Исключением являлся П. Н. Милюков, министр иностранных дел. А из последнего состава Временного правительства только А. В. Карташов, первый министр по делам вероисповеданий, не был членом масонских лож. Лидеры всех политических партий — от октябристов до меньшевиков - также были членами масонских лож [2]. Масоны, как известно, несли ответственность не перед своим государством, а перед своей ложей. А ложи имели конкретные места прописки.

Другие влияние внешнего фактора в событиях 1917 г. освещают с геополитических позиций: с начала XX в. резко обострилась борьба за ресурсы. Произошло это в силу завершения территориального контроля над сушей. С этой точки зрения Россия оказалась очень привлекательным призом в борьбе за глобальные ресурсы. Поэтому прежде всего Британская империя стремилась не допустить 
поступательного движения России, ее доминирования в мире и Европе как в экономическом, военном, так и в культурно-духовном отношении. С таких позиций написаны ставшие популярными работы Н. В. Старикова и А. И. Фурсова, в которых революция в России представлена в большей степени как спецоперация внешних сил [3-6].

Нет единства относительно 1917 г. в России и среди западных историков. Только в американской историографии имеется девять концепций Октябрьской революции [7, с. 254].

В силу этого в связи с накопленными новыми данными, появившимся огромным пластом эмигрантской литературы существует потребность в интерпретации предпосылок политических процессов 1917 г. с опорой на различные методологические подходы и через призму исторического опыта, в том числе и постсоветского периода. На это обращает внимание известный специалист в области методологии исторического познания А. Н. Медушевский [8].

Исследователи региональных революционных процессов должны ответить на сфрормулированные сегодня ффундаментальные вопросы: вызревали объективные причины социальных катаклизмов в регионах или это была городская революция, последствия которой были навязаны регионам, либо речь идет о государственном перевороте, в котором решающую роль сыграли инонациональные силы?

Ответы на данные вопросы требуют анализа политических процессов в сибирском регионе в широком контексте. Хронологически анализ необходимо начинать с реформ Александра II, заложивших основы движения России по капиталистическому пути. При этом нужно учитывать влияние социокультурного и регионального своеобразия огромного сибирского пространства. В какой степени в совокупности они могли влиять на формирование предпосылок Октябрьской революции 1917 г.?

Спецификой Сибири являлось то, что земельный вопрос здесь не имел столь острого характера, как в европейской части России. Сибирь не знала практики крепостного состояния, не было здесь и дворянский имений. В европейской части страны на душу мужского пола в 1880 г. приходилось 3,5 десятины. В Иркутской же губернии в 1880-х гг. на душу мужского пола приходилось по 23,8 десятины удобной земли, т. е. в восемь раз больше [9, с. 37]. И хотя диффреренциация земельной собственности была существенной, однако и с этой точки зрения серьезные социальные потрясения Сибири не грозили.

В исследованиях историков, особенно советского периода, отмечается, что протестные настроения стимулировались спецификой положения Сибири в административно-государственном устройстве. В этой специфике можно выделить три аспекта.

Первый связан со статусом Сибири, который мало чем отличался от статуса колонии. Сибирь рассматривалась как источник ресурсов для Европейской России, и эти ресурсы без особых вложений в социальную инфраструктуру региона укрепляли мощь империи. Однако такое положение характерно не только для того периода. В настоящее время отношения между центром и периферией вряд ли принципиально отличаются от тех, что имели место в начале XX в. В целом такая ситуация характерна для крупных государств, что подметил еще Ш. Монтескье в своем знаменитом труде "О духе законов», отмечая практику «опустошения окраин» в больших государствах [10, с. 125].

Второй аспект связан с гипертрофированным сосредоточением власти в руках губернаторов, которые имели значительную автономию в решении многих вопросов. Деспотия со стороны «наместников» интерпретируется как фактор, стимулирующий протестные настроения в Сибири. Однако такое властное осуществление своих полномочий характерно не только для Сибири, но и для России, и именно управление в «ручном режиме» является особенностью территориально крупных государств [там же, с. 119]. С этой точки зрения при других способах организации государственной власти накал протестных настроений мог быть значительно выше.

Третий аспект. Можно предположить, что радикализация общественных отношений была связана с так называемым национальным вопросом. Однако в исторической литературе национальный вопрос предельно политизирован и всегда используется в угоду определенной идеологии в целях манипулирования общественным сознанием. Первыми эту тему стали поднимать представители областнического движения, обвиняя самодержавие в пагубном влиянии русской государственности на аборигенов. Национальный вопрос раздувала русская интеллигенция в лице разночинцев. Делали они это осознанно в силу своих убеждений или в силу того, что в борьбе с царизмом все средства хороши, вопрос остается открытым. Затем, но уже с вульгарных позиций марксистско-ленинской идеологии в первые десятилетия советской 
власти политика царизма провозглашалась в национальном вопросе империалистической, а недовольство местной знати и стычки на бытовой почве трактовались как проявление национально-освободительной борьбы местного населения. Именно с этих позиций, например, написана монография известного сибирского историка А. П. Окладникова, изданная в 1937 г. [11]. После распада СССР уже национальная политика советского государства во многих публикациях стала оцениваться с позиций идеологии либерализма. Поэтому весь советский политический режим теперь рисуется только в черных красках. В подобных работах утверждается, что материальные ресурсы коренных народов Сибири использовались «для нового строительства», и это неизбежно вело к «депопуляции» местного населения. Обобщающие цифры и факты, свидетельствующие о «депопуляции», в подобных публикациях отсутствуют, поскольку их «реальные масштабы не оценены до сих пор». Данные утверждения удивительно совпадают с выводами областнического движения, только вина в них возлагается уже на советскую власть: «Советская государственная модель поведения в отношении малых народов в 1930-е гг. не предусматривала особого учета национальной специфики регионов... коренных групп населения». Решением возникающих проблем становилось «физическое уничтожение национальных кадров под вымышленными предлогами» [12, с. 476-478; 13, с. 143-148].

На этой теме можно бесконечно спекулировать, представлять царскую и советскую Россию "тюрьмой народов», но разбор этих завалов вряд ли приблизит нас к пониманию причин такой быстрой радикализации общественных настроений в 1917 г.

В рамках материалистического понимания политических процессов рассматривается история капиталистического развития России со второй половины XIX в. Именно в этот период начала формироваться социальная основа будущих протестных выступлений. Существующая политическая система не учитывала данные изменения, что неизбежно с точки зрения такого подхода должно было сопровождаться обострением общественных отношений. Это вопрос о реальном местном политическом пространстве и возможности диалога населения с властью.

Анализ этой проблемы свидетельствует, что политические права и свободы в рамках местного самоуправления в регионе постепенно наполнялись вполне реальным содержанием. Если понимать под содержанием демократии развитое местное самоуправление, в рамках которого граждане реально учатся управлять и реализовывать свои интересы, то в этом смысле в рамках городского управления в Иркутске нарабатывался опыт и имелась прослойка людей, активно включавшихся в обустройство различных сорер городской жизни. Расширение избирательных прав, начиная с введения городового уложения (введено в Иркутске в 1872 г.), постепенно увеличивало количество граждан, вовлеченных в процесс фрормирования городских органов власти. И хотя в этом процессе принимали участие не более 6,3 \% иркутян, по этому показателю Иркутск почти в два раза превышал аналогичный показатель в городах Европейской России [9, с. 127]. Реально же даже этим существующим правом пользовалась лишь незначительная часть сословий. По итогам первых четырех выборов в городскую думу в них принимали участие от 6,5 до 20,0 \% горожан, обладающих избирательным правом. То есть не было желания самостоятельно обустраивать городскую среду даже у тех, кто имел и ресурсы, и власть. Что дало бы в этих условиях введение всеобщего равного избирательного права?

Со временем городская дума все больше проявляла себя как общественно-политический орган, актуализирующий перед властью местные нужды. Параллельно в самой системе органов местного самоуправления оформлялась оппозиция, и таким образом нарабатывался не только опыт политической борьбы, но и избранные депутаты (гласные) оказывались под контролем оппозиции. То есть начинали действовать классические демократические механизмы. Реальное влияние местных органов власти к началу $X X$ в. выросло настолько, что они стали ставить вопрос о запрещении ссылки в Сибирь [14, с. 103], в годы Русско-японской войны городская дума даже могла отказать военному ведомству в отведении земли под госпиталь. За каких-то 30 лет местные органы власти набрали значительный вес, авторитет и приобрели статус, с которым государственная власть была вынуждена считаться.

Наряду с развитием органов местного самоуправления шел процесс становления неполитических и политических объединений города. Первоначально они создавались по инициативе губернской власти, однако уже к концу XIX в. из учтенных 45 неполитических общественных формирований только 18 объединений (40\%) были открыты административным порядком $[9$, с. 146]. 
Таким образом, в пореформенный период в Иркутске отчетливо прослеживается тенденция формирования структур гражданского общества, которые являются основой постепенной трансформации авторитарной монархии во вполне демократический политический режим. При эволюционном процессе развития данная альтернатива становилась совершенно реальной.

Оппозиционные настроения по отношению к самодержавию имели место в позиции органов местного самоуправления. Но есть ли здесь что-то, выходящее за рамки? В рамках местного самоуправления всегда идет процесс жесткого позиционирования с органами государственной власти. Это нормальное противостояние при согласовании местных и общегосударственных интересов в рамках управленческих структур, и наличие такого противостояния даже с большой натяжкой вряд ли можно относить к объективным предпосылкам социалистической революции.

Наличие значительного количества ссыльных в Сибири также можно рассматривать как фрактор, способствующий радикализации политических настроений. В действительности никаких «потоков узников» царизма в Сибирь не было. Иркутский историк Н. Н. Щербаков еще в середине 1970-х гг. в результате напряженных изысканий в архивах изложил достоверные данные о количестве ссыльных в сибирский регион: на 1907 г. - всего около 2 тыс. чел.; на 1912-й - более 7 тыс. и на 1917-й - чуть больше 14 тыс. ссыльных [15, с. 457]. Эта цифра более чем в пять раз меньше приводимой в третьем томе «Истории Сибири», изданном в 1968 г. [16, с. 327]. Для огромного сибирского пространства это ничто. Но дело не только в этом. Численно в ссылке преобладали социал-демократы, но большевики среди них составляли меньшинство. При этом не было единства в рядах тех, кто занимал наиболее радикальные позиции по отношению к власти. Оппозиционно настроенная интеллигенции Иркутска и политические ссыльные дробились на различные политические платформы и союзы и не представляли собой единой организованной силы. При этом сразу после февральских событий 1917 г. подавляющая часть политических ссыльных (свыше 3 тыс. чел.) убыла из Иркутской губернии в центральные районы страны.

О том, что политические ссыльные в регионе не были реальной угрозой для государства, свидетельствует вполне лояльное отношение к ним со стороны власти. Общение с политическими ссыльными в условиях неразвитости сореры услуг для своего време- ни являлось еще и формой досуга. Применительно к американскому обществу эти аспекты были изложены в работе А. де Токвиля «Демократия в Америке», ставшей классикой политической мысли [17]. Именно поэтому в иркутском обществе представители государственной власти относились к политическим ссыльным весьма снисходительно.

Что в итоге? До 1917 г. в регионе отсутствовали серьезные социальные, политические, экономические предпосылки для радикальной смены общественного строя. Имеющиеся противоречия вполне могли разрешаться в рамках существующей системы. Это понимали и сами большевики. Ситуация начала радикально меняться с начала 1917 г. Точкой отсчета, когда были запущены политические процессы, приведшие к Октябрю, стал государственный переворот в феврале 1917 г. Действия Временного правительства вели к хаотизации общественных отношений в России.

В годы войны, когда она в целом шла к успешному завершению, отстраняют от власти главу государства и верховного главнокомандующего, в итоге обнуляется присяга.

Распускают жандармерию и выпускают из тюрем политических, что резко обостряет борьбу за власть, прежде всего в центре, куда хлынула подавляющая часть ссыльных.

Распускают полицию и выпускают из тюрем уголовников. В результате происходит быстрое увеличение преступности (грабежи, убийства, воровство), и, как следствие, растет социальная напряженность.

Ликвидируется вся устоявшаяся вертикаль власти. Губернаторов устраняют, вместо них назначаются комиссары Временного правительства. На местные органы власти возлагают обязанности государственного управления, но они не обладают ни опытом, ни авторитетом, позволяющим эфффективно бороться на местах с усиливающимся хаосом, обеспечивать военные поставки и выполнять военный заказ. Справиться с проблемами на базе той политической платформы, на которой стояли местные органы власти, в условиях нарастающего хаоса было невозможно.

В условиях войны Временное правительство объявляет о проведении крупнейшей политической реформы, связанной с определением будущего политического строя России. В воюющей стране организуют выборы в Учредительное собрание, что сопровождается резкой активизацией политической борьбы и популистскими заявлениями. В условиях быстро ухудшающейся ситуации Временное 
правительство заявляет, что политические реформы будут осуществляться независимо от «военных обстоятельств» [18, с. 14-16].

Но важнейшим фактором, предопределившим победу большевиков, явилось разложение русской армии. Солдатские массы охотно соглашались с созданием солдатских комитетов. Весной 1917 г. на фронте были узаконены и солдатские митинги. Поскольку бунтовать было вполне законно, то солдаты бунтовалиибез пропагандыбольшевиков [19, с. 109]. А после этого от Временного правительства последовали такие документы, как «Декларация прав солдата», введение института комиссаров Временного правительства, на которых возлагалось гражданское управление на театре войны [20, с. 9-10]. В этих условиях провозглашение лозунга «Война до победного конца!» способствовало быстрому переходу армейских частей на сторону большевиков, которые предложили выход из войны и заключение демократического мира без всяких контрибуций.

В такой ситуации реальная власть быстро перетекает на сторону тех политических сил, которые поддерживает армия и население крупнейших индустриальных и политических центров. Аморфное «демократическое большинство» ничего не решает в настоящем, не решало оно и в прошлом. Интерполяция политического опыта на события в регионе подтверждает подобную логику событий. На состоявшихся в июле 1917 г. выборах в Иркутскую городскую думу большевики получили всего 11 мандатов из 90, тогда как у эсеров было 47 мест. Выборы же в Учредительное собрание спустя четыре месяца, в ноябре 1917 г., продемонстрировали уже совершенно иную ситуацию. Большевики в городе получили 37,0 \% голосов, а эсеры $32,5 \%$ [9, с. 443]. При этом за большевиков проголосовали солдаты Иркутского гарнизона. Победа в губернском центре с таким влиянием в армейских частях имела решающее значение. Голоса крестьянской массы, отданные за эсеров и другие политические силы, разбросанные по территории региона, в данном случае не имели столь серьезного значения. Поэтому в условиях массовой поддержки большевиков со стороны солдатских масс и крупнейших индустриальных центров политически ситуация была безальтернативной. Триумфальное шествие советской власти - это реальный и закономерный итог деятельности Временного правительства. То есть Октябрьский переворот является прямым следствием не каких-то объективных предпосылок, а тех процессов, которые были заданы февральским государственным переворотом. Запущенные переворотом в ходе войны политические процессы способствовали дезорганизации общественных отношений в регионе и, как следствие, вызвали рост протестных настроений. Решающим фрактором, обеспечившим победу большевиков, стал переход на их сторону солдатских масс. Анализ процессов, происходивших в феврале 1917 г. в результате государственного переворота, не позволяет говорить о наличии каких-либо еще реальных альтернатив, кроме большевистской. Как отмечал Алекс Бэттлер, «непредсказуемое направление - утверждение неверное хотя бы уже потому, что у исторического развития человечества не так уж много альтернатив... Их несложно вычислить из тенденций, которые обозначились...» [21, с. 212].

Что в итоге? Политические процессы, приведшие к Октябрю, были запущены февральским переворотом. Технология этого переворота весьма близка к технологии современных государственных переворотов, именуемых ныне «цветными революциями», осуществляющихся под контролем внешних сил. Поэтому концептуальное осмысление политических процессов накануне Октябрьской революции требует закрытия многочисленных лакун в историческом познании, связанных с инспирированием данных процессов в столице России в фреврале 1917 г. Поскольку ни одна сколь-нибудь масштабная революция в XX в. не происходила без влияния внешнего субъекта, события 1917 г. также требуется вписать в мировой контекст.

В существовавшем на то время геополитическом раскладе присутствовали интересы правых глобалистов, стремившихся к разрушению европейских империй, и левых глобалистов (Ленин, Троцкий), ориентированных на мировую революцию. Были и интересы Германии на ослабление России и как минимум на вывод ее из этой войны. Государственный переворот в феврале 1917 г. и деятельность Временного правительства нельзя рассматривать вне этих разноплановых сил.

Борьба за власть всегда основана на ресурсах. Успех в этой борьбе, как правило, на стороне тех, у кого больше наличных ресурсов. Вопрос о финансировании оппозиционной политической деятельности в России - один из самых мало изученных историками. Анализ источников фринансирования революционной деятельности со стороны разноплановых сил, заинтересованных в переформатировании российского пространства, позволит ответить на многие 
вопросы, связанные с инициированием распада Российской империи.

Таким образом, без исследования и осмысления геополитических перипетий мировой политики, влияния внешнего субъекта в подготовке и осуществлении государственного переворота в Феврале 1917 г. и его активного участия в достижении своих долгосрочных интересов в отношении России невозможно оценить воздействие внутреннего субъекта и выстроить полноценную концепцию политических процессов, завершившихся утверждением советского проекта.

\section{СПИСОК ИСПОЛЬЗОВАННОЙ ЛИТЕРАТУРЫ}

1. Минц И. И. История Великого Октября : в 3 т. / И. И. Минц. - 2-е изд. - М. : Наука, 1977-1979. - 3 т.

2. Берберова Н. Н. Люди и ложи. Русские масоны XX столетия / Н. Н. Берберова. - М. : ПрогрессТрадиция, 1997. - 58 с.

3. Стариков Н. В. Ликвидация России. Кто помог красным победить в Гражданской войне / Н. В. Стариков. СПб. : Питер, 2014. - 384 с.

4. Стариков Н. В. 1917. Разгадка «русской» революции / Н. В. Стариков. - СПб. : Питер, 2013. - 416 с.

5. Стариков Н. В. Кто финансирует развал России. От террористов до моджахедов / Н. В. Стариков. СПб. : Питер, 2010. - 288 с.

6. Фурсов А. Россия на пороге нового мира. Холодный восточный ветер - 2 / А. Фурсов. - М. : Кн. мир, 2016. $-384 \mathrm{c}$.

7. Хартова Е. С. Октябрьская революция - случайность или закономерность? От Февраля к Октябрю/ Е. С. Хартова // Наше Отечество. Страницы истории : сб. науч. тр. / под ред. В. С. Порохни. - М. : Тип. «Наука», 2017. - Вып. 13. - С. 254-262.

8. Медушевский А. Н. Историки об историках. Научное сообщество и его критики: старые обиды, новые разочарования и незавершенный поиск идентичности / А. Н. Медушевский / / Российская история. - 2012. № 4. - С. 203-208.

9. Иркутск накануне и в 1917 году. Очерки политической истории губернского центра / под ред. Л. М. Дамешека. - Иркутск : Оттиск, 2017. - 544 с.

10. Монтескье Ш. О духе законов [Электронный ресурс] / Ш. Монтескье. - Режим доступа : http:// www.civisbook.ru/files/File/Monteskye.O dukhe.pdf.

11. Окладников А. П. Очерки из истории западных бурят-монголов / А. П. Окладников. - Улан-Удэ : НоваПринт, 2014. - 514 с.

12. Папков С. А. Сталинизм в судьбе малых народов Сибири / С. А. Папков // Советские нации и национальная политика в 1920-1950-е годы : материалы 6-й междунар. науч. конф., Киев, 10-12 окт. 2013 г. М. : Полит. энцикл., 2014. - С. 478-486.

13. Папков С. А. Обыкновенный террор. Политика сталинизма в Сибири / С. А. Папков. - М. : РОССПЭН, 2012. $-440 \mathrm{c}$.

14. Иванов А. А. Проект И. И. Попова о введении земств в Сибири, выработанный в Иркутске накануне первой русской революции / А. А. Иванов, В. В. Андреев // Известия Иркутского государственного университета. Сер.: Политология. Религиоведение. - 2017. - Т. 22. - С. 102-109.

15. Иванов А. А. Личный фонд Н. Н. Щербакова в государственном архиве Иркутской области / А. А. Иванов // Иркутский историко-экономический ежегодник, 2018. - Иркутск : Изд-во БГУ, 2018. C. $456-462$.

16. История Сибири с древнейших времен до наших дней / В. И. Дулов [и др.] ; ред. А. П. Окладников, В. И. Шунков. - Л. : Наука, 1968. - Т. 3 : Сибирь в эпоху капитализма. - 530 с.

17. Токвиль А. де. Демократия в Америке : пер. с фр. / А. де Токвиль. - М. : Прогресс, 1992. - 554 с.

18. Хрестоматия по истории России, 1917-1940 / ред. М. Е. Главацкий. - М. : Аспект Пресс, 1995. - 455 с.

19. Базанов С. Н. Эволюция доверия солдат-фронтовиков к Временному правительству / С. Н. Базанов // Идеология и политика в истории России : сб. ст. - М. : АИРО-ХХІ, 2016. - С. 108-117.

20. Бакланова И. С. К вопросу о строительстве российской армии в 1917 году (историографический аспект) / И. С. Бакланова // Наше Отечество. Страницы истории : сб. науч. тр. / под ред. В. С. Порохни. - М. : Тип. «Наука», 2017. - Вып. 13. - С. 5-19.

21. Бэттлер А. Мирология. Прогресс и сила в мировых отношениях / А. Бэттлер. - М. : Изд-во ИТРК, 2015. - Т. 2 : Борьба всех против всех. - 672 с.

\section{REFERENCES}

1. Mints I. I. Istoriya Velikogo Oktyabrya [The Great October History]. 2nd ed. Moscow, Nauka Publ., 1977-1979. 3 vol.

2. Berberova N. N. Lyudi i lozhi. Russkie masony XX stoletiya [People and Lodges. Russian Masons of the $20^{\text {th }}$ century]. Moscow, Progress-Traditsiya Publ., 1997. 58 p.

3. Starikov N. V. Likvidatsiya Rossii. Kto pomog krasnym pobedit' v Grazhdanskoi voine [Liquidation of Russia. Who Helped the Red Army Win in the Civil War]. Saint Petersburg, Piter Publ., 2014. 384 p.

4. Starikov N. V. 1917. Razgadka "russkoi» revolyutsii [1917. The Key to the «Russian» Revolution]. Saint Petersburg, Piter Publ., 2013. 416 p.

5. Starikov N. V. Kto finansiruet razval Rossii. Ot terroristov do modzhakhedov [Who is financing Russia's downfall. From Terrorists to Mujahiddin]. Saint Petersburg, Piter Publ., 2010. 288 p. 
6. Fursov A. Rossiya na poroge novogo mira. Kholodnyi vostochnyi veter -2 [Russia at the Threshold of the New World. The Cold Eastern Wind - 2]. Moscow, Knizhnyi mir Publ., 2016. 384 p.

7. Khartova E. S. Is the October Revolution Accidental or Expected? From February to October. In Porokhnya V. S. (ed.). Nashe otechestvo. Stranitsy istorii [Our Motherland. Pages of History]. Moscow, Tipografiya «Nauka» Publ., 2017, iss. 13, pp. 254-262. (In Russian).

8. Medushevskii A. N. Historians about Historians. The Academic Community and its Critics: Old Scores, New Disappointments and Uncompleted Identity Search. Rossiiskaya istoriya = History of Russia, 2012, no. 4, pp. 203208. (In Russian).

9. Dameshek L. M. (ed.). Irkutsk nakanune iv 1917 godu. Ocherki politicheskoi istorii gubernskogo tsentra [lrkutsk on the eve and in 1917. Essays on the Political History of the Governorate's Centre]. Irkutsk, Ottisk Publ., 2017. $544 \mathrm{p}$.

10. Montesquieu Ch. De l'esprit des lois. Paris, 1803. 274 p. (Russ. ed.: Montesquieu Ch. O dukhe zakonov. Available at: http://www.civisbook.ru/files/File/Monteskye.O dukhe.pdf).

11. Okladnikov A. P. Ocherki iz istorii zapadnykh buryat-mongolov [Essays on the History of Western Buryat-Mongols]. Ulan-Ude, Novaprint Publ., 2014. 514 p.

12. Papkov S. A. Stalinism in the Life of the Small Peoples of Siberia. Sovetskie natsii $i$ natsionalnaya politika $v$ 1920-1950-e gody. Materialy 6-i mezhdunarodnoi nauchnoi konferentsii, Kiev, 10-12 oktyabrya $2013 \mathrm{~g}$. [Soviet Nations and National Policy in 1920-1950. Materials of International Scientific Conference, Kiev, October 1012, 2013]. Moscow, Politicheskaya entsiklopediya Publ., 2014, pp. 478-486. (In Russian).

13. Papkov S. A. Obyknovennyi terror. Politika stalinizma v Sibiri [Ordinary Violence. Stalinism Policy in Siberia]. Moscow, Rosspen Publ., 2012. 440 p.

14. Ivanov A. A., Andreyev V. V. I. I. Popov's Project about Introducing Zemstvos (Counties) in Siberia, Worked in Irkutsk out on the Eve of the First Russian Revolution. Izvestiya Irkutskogo gosudarstvennogo universiteta. Seriya: Politologiya. Religiovedenie = The Bulletin of Irkutsk State University. Series: Political Science and Religion Studies, 2017, vol. 22, pp. 102-109. (In Russian).

15. Ivanov A. A. Shcherbakov's Papers in the State Archive of the Irkutsk Region. Irkutskii istoriko-ekonomicheskii ezhegodnik, 2018 [Irkutsk History and Economics Annual Bulletin, 2018]. Irkutsk, Baikal State University Publ., 2018, pp. 456-462. (In Russian).

16. Dulov V. I. [et al.] ; Okladnikov A. P., Shunkov V. I. (ed.). Istoriya Sibiri s drevneishikh vremen do nashikh dnei [History of Siberia from the Ancient Times to Our Days]. Leningrad, Nauka Publ., 1968, vol. 3. 530 p.

17. Tocqueville A. de. De la Démocratie en Amérique. Paris, 1835. 367 p. (Russ. ed.: Tocqueville A. de. Demokratiyav Amerike. Moscow, Progress Publ., 1992. 554 p.).

18. Glavatskii M. E. (ed.). Khrestomatiya po istorii Rossii, 1917-1940 [Russian History Reader, 1917-1940]. Moscow, Aspekt Press Publ., 1995. 455 p.

19. Bazanov S. N. Evolution of Trust of Front-Line Soldiers in the Provisional Government. Ideologiya i politika $v$ istorii Rossii [ldeology and Politics in the Russian History]. Moscow, AIRO-XXI Publ., 2016, pp. 108-117. (In Russian).

20. Baklanova I. S. On the Issue of Formation of the Russian Army in 1917 (Historiographical Aspect). In Porokhnya V. S. (ed.). Nashe otechestvo. Stranitsy istorii [Our Motherland. Pages of History]. Moscow, Tipografiya «Nauka» Publ., 2017, iss. 13, pp. 5-19. (In Russian).

21. Bettler A. Mirologiya. progress i sila v mirovykh otnosheniyakh [World Studies. Progress and Power in the World Relations]. Moscow, ITRK Publ., 2015. Vol. 2. 672 p.

\section{Информация об авторе}

Шалак Александр Васильевич - доктор исторических наук, профессор, заведующий кафедрой истории и международных отношений, Байкальский государственный университет, 664003, г. Иркутск, ул. Ленина, 11, e-mail: ShalakAV@bgu.ru.

\section{Для цитирования}

Шалак А. В. Российская революция 1917 года в региональном преломлении: проблемы познания / А. В. Шалак / / Известия Байкальского государственного университета. - 2018. - Т. 28, № 2. - С. 300307. -DOI: 10.17150/2500-2759.2018.28(2).300-307.

\section{Author}

Alexander V. Shalak - D.Sc. in History, Professor, Head of the Department of History and International Relations, Baikal State University, 11 Lenin St., 664003, Irkutsk, the Russian Federation, e-mail: ShalakAV@bgu.ru.

\section{For citation}

Shalak A. V. Russian Revolution of 1917 from the Regional Perspective: Perception Issues. Izvestiya Baykal'skogo gosudarstvennogo universiteta $=$ Bulletin of Baikal State University, 2018, vol. 28, no. 2, pp. 300307. DOI: 10.17150/2500-2759.2018.28(2).300-307. (In Russian). 